\title{
Pens

\section{"¿ES EL TEXTO UN CUERPO Y EL CUERPO, UN TEXTO?". AUTORREPRESENTACIÓN Y POSICIONAMIENTO FEMINISTA EN MARTA SANZ}

\author{
"IS THE TEXT A BODY AND THE BODY, A TEXT?". SELF-REPRESENTATION
} AND FEMINIST STANCES IN MARTA SANZ

Gema Baños Palacios

Universidad Autónoma de Madrid

gema.bannos@uam.es

Recibido: 19.03.2021

Aceptado: 19.11.2021

RESUMEN: En este artículo nos proponemos una revisión de las principales estrategias de autorrepresentación de la autora española Marta Sanz, desplegadas tanto en sus artículos periodísticos y ensayos como en sus novelas de corte autobiográfico. Sanz no vacila en defender una literatura incómoda que provoque una agitación en sus lectores, una reacción crítica, reclamando una posición en la que dar visibilidad a algunos temas que han sido menospreciados y excluidos de la tradición literaria por ser considerados íntimos y, por tanto, no universales. La mirada con la que Sanz taladra la realidad se encuentra atravesada por su activismo feminista, pues le resulta imposible no reclamar una perspectiva de género. En sus obras asistimos a la exhibición de su autorretrato, una obra para la que demanda su posición de sujeto que escoge mostrarse a los demás, subvirtiendo la mirada fetichista masculina. No sólo conseguirá afirmarse como mujer y autora a través de sus textos, sino que se mantendrá en perpetua lucha frente a los estereotipos de representación de la violencia hacia las mujeres en la literatura. La autora consigue hacer del texto, un cuerpo; un verdadero corpus en el que, a modo de espejo, se canaliza el dolor, la emoción, lo obsceno. Un discurso que se encarna para decir con autenticidad todo lo que históricamente ha sido acallado.

PALABRAS CLAVE: Autoría, estudios de género, literatura española, feminismo, autobiografía, corporalidad, representaciones subversivas

AвSTRACT: In this article we propose a review of the main strategies of self-representation of the Spanish author Marta Sanz, deployed both in her journalistic 
articles and essays and in her autobiographical novels. Sanz does not hesitate to defend an uncomfortable literature that provokes an agitation in her readers, a critical reaction, so that in her texts she claims a position in which to give visibility to some subjects that have been undervalued and excluded from the literary tradition, since they were considered intimate subjects and, therefore, not universal. The gaze with which Sanz drills reality is crossed by her feminist activism, as it is impossible for her not to claim a gender perspective. In her works we witness the exhibition of her self-portrait, a work for which she demands her position as a subject who chooses to show herself to others, in a way that subverts the male fetishist gaze. Not only will she succeed in affirming herself as a woman and author through her texts, but she will also maintain herself in a perpetual struggle against the stereotypical representation of violence against women in literature. The author manages to make the text, a body, a real corpus in which, as a mirror, pain, emotion, and obscenity are channeled. A discourse that is embodied to say with authenticity everything that historically has been silenced.

KEYwORDS: Authorship, Gender studies, Spanish literature, Feminism, Autobiography, Corporeality, Subversive representations

\section{0}

\section{Nos estamos pensando: la mirada feminista en Marta SANZ}

A la luz de la llamada "cuarta ola" feminista, que ha ido cobrando un papel destacado en la conciencia política y social durante los últimos cinco o seis años, queremos aproximarnos a la escritura de Marta Sanz (Madrid, 1967), que hilvana su discurso a partir del afianzamiento del cuerpo como lugar de enunciación y altavoz crítico para poder nombrar a un sujeto femenino dentro del contexto sociocultural actual. Si bien la autora posee una trayectoria sólida -aunque posiblemente no tan reconocida por la crítica como cabría esperar-, nos parece que es una de las escritoras que con mayor ahínco ha definido su postura autorial desde la ideología y el compromiso con el feminismo. En este artículo intentaremos responder al interrogante que se plantea como título - “ies el texto un cuerpo y el cuerpo, un texto?"-, enunciado por la propia autora en una de sus obras (2019: 98). Para ello partiremos de algunas de las reflexiones y propuestas defendidas por Sanz en los ensayos Monstruas y centauras. Nuevos lenguajes del feminismo (2018) y No tan incendiario (2019), así como de algunos artículos de opinión donde se interroga constantemente sobre los obstáculos a los que ha de hacer frente como mujer y autora dentro del campo cultural. Tal y como ha subrayado la crítica (Somolinos Molina 2018), en Sanz se produce una rica intersección entre las variables de género y clase, así como de su relación con el trabajo, de manera que será preciso examinar cómo se traduce esa huella corporal en sus textos literarios. Con el fin de rastrear la imbricación entre las autorrepresentaciones y el compromiso del sujeto con el feminismo, nos detendremos a examinar las estrategias de representación urdidas 
por la escritora en dos obras de corte autobiográfico, La lección de anatomía (2014) y Clavícula (2017), y una tercera de carácter ficcional pero que aborda sin tapujos el tema de la violencia contra las mujeres y sus cuerpos, pequeñas mujeres rojas (2020). Esta selección nos parece significativa porque traza una trayectoria plenamente coherente en la que se pone de relieve la emergencia de una escritura del cuerpo, de una voz autorial que es ante todo carnal, tal y como ya han resaltado investigaciones precedentes. ${ }^{1}$

El ensayo de Marta Sanz en el que más claramente ha permitido que su palabra se convirtiera en altavoz para el feminismo es Monstruas y centauras. Nuevos lenguajes del feminismo, publicado en Anagrama en 2018. Resulta oportuno señalar que su publicación se enmarca en un contexto cultural en el que, desde los últimos años, se han multiplicado de forma muy notable tanto reediciones de obras clásicas del feminismo como ediciones de nuevos ensayos que se plantean desde diferentes perspectivas la incidencia de esta cuarta ola. Así, en los mostradores de las librerías conviven Un cuarto propio, de Virginia Woolf (Lumen, 2018); Vindicación de los derechos de la mujer, de Mary Wollstonecraft (Montena, 2019 y Penguin Random House, 2020); o la primera edición en español de Cómo acabar con la escritura de las mujeres, de Joanna Russ (Barrett, 2018). Además, han aparecido numerosos estudios y análisis como ¿Qué es una autora? Encrucijadas entre género y autoría, editado por Aina Pérez Fontdevila y Meri Torras (2019); Ahora, feminismo, de Amelia Valcárcel (2019); o las obras de Nuria Varela Feminismo 4.0. La cuarta ola (2019) y Cansadas: una reacción feminista ante la nueva misoginia (2017).

Todas estas publicaciones son muestra del creciente interés hacia un abanico de discursos que, tradicionalmente, se habían situado en los márgenes del canon $y$, por tanto, dejaban en la oscuridad una gran parte de las experiencias de las mujeres. Dentro de este panorama nos encontramos con el conjunto de ensayos de Sanz Monstruas y centauras. Resulta muy significativa la elección de los dos términos del título, ${ }^{2}$ no solo porque no se encuentran admitidos con el morfema de género femenino en el Diccionario de la Real Academia, sino porque aluden a criaturas alejadas de lo humano, pertenecientes a un ámbito mítico o fantástico. En "La excepción y lo ordinario", Christine Planté (2019) analiza las representaciones decimonónicas de la mujer autora y señala que, en tanto que excepción a la regla de su sexo y a la de la creación literaria, a menudo las escritoras eran tachadas de "monstruo". ${ }^{3}$ El título escogido por Sanz remite a una

\footnotetext{
${ }^{1}$ La crítica coincide en señalar la novela Daniela Astor y la caja negra (2013) como otra de las obras en las que Sanz despliega una crítica de la violencia contra los cuerpos de las mujeres en la España de la Transición. Pese a que no abordaremos esta obra directamente en el artículo, sí haremos referencia a ella en algunos casos concretos.

2 La elección de estos términos probablemente se corresponda con una estrategia empleada por la autora en sus columnas de opinión en El País, en las que, como ella misma explica, se sirve de una pequeña travesura (transformar al femenino algunos vocablos que no lo poseen): el lenguaje inclusivo desde un enfoque crítico no exento de ironía. Así lo explica en su artículo "Académica".

3 Para entender mejor esta reflexión hay que considerar el hecho de que existen dos niveles de excepción en el siglo xIx: por un lado, el sexo femenino se percibe como una excepción del género humano ya que goza de ciertos "privilegios" (están exentas de participación política) y además no
} 
experiencia biográfica de la adolescencia, un ejercicio creativo e inocente, pero al mismo tiempo profundamente ideológico, que describe con estas palabras: ${ }^{4}$

Yo también escribí un cuaderno de monstruas y centauras: las monstruas eran
mujeres patchwork, construidas a partir de fragmentos de cuerpos de revis-
ta, las extrañas construcciones recortables de una púber que iba buscando la
perfección de un canon de belleza femenina y el sueño de su razón produjo
monstruos, monstruas, centauras, siluetas rotas por las tijeras, corroídas por el
pegamento. (Sanz 2018b: 105)

De este modo, el texto que Sanz nos presenta comparte en cierto modo la búsqueda de una construcción, pero, sobre todo, de una deconstrucción de muchas de las tensiones que se dibujan en los cuerpos de las mujeres cuando se detienen a plantearse los conflictos latentes dentro del sistema patriarcal dominante. La autora parte del contexto de la huelga feminista convocada el 8 de marzo de 2018 y de su participación, junto a su amiga Elvira, en la multitudinaria manifestación de Madrid. Mientras recorren la manifestación tomadas del brazo, las amigas dan voz a sus propios relatos identitarios, pero también se cuelan en su diálogo personajes literarios como La Colometa, protagonista de La plaça del diamant, de Mercè Rodoreda, o las trabajadoras del tea room de la novela de Luisa Carnés, así como fragmentos de diversos reportajes publicados en prensa que aportan datos objetivos y cifras que atestiguan la persistente desigualdad de las mujeres en nuestro país, más pronunciada en el sector de las trabajadoras precarias. Sanz entrelaza audazmente la literatura con un malestar creciente causado por la degeneración de la cultura, por la relación tensa que se produce entre las diversas producciones artísticas y su inscripción dentro del sistema capitalista sustentado en el consumo. Escuchamos su grito, en el que ya no puede emerger ni un asomo de pudor, porque, a pesar de que, como autora, se sabe en una posición de cierto reconocimiento, en innumerables ocasiones siente que debe reforzar su legitimidad como escritora, dado que todavía siguen encontrando su espacio una lluvia de prejuicios y de "moldes" con los que se encasilla a las mujeres y se las rechaza con vehemencia. Así, Sanz exclama:

Grito también contra mi civilización, pero no contra toda. Contra que la carne se acomode en esos moldes -a esos tipos de imprenta-que secularmente vienen preparando para mí y mis congéneres: puta, madre, santa, bella sin alma, fea, marisabidilla, estéril, egoísta, loca, histérica, marimandona. (Sanz 2018b: 35)

\footnotetext{
pueden proclamarse como singulares porque, de ser así, se las considera locas o excepcionales, entendiendo su éxito como algo anómalo, monstruoso. La excepcionalidad se convierte en una trampa que polariza a las mujeres en dos grupos, la excepción y lo ordinario.

${ }^{4}$ En su novela Daniela Astor y la caja negra, la protagonista es una apasionada de la práctica del collage y en ella vuelca su obsesión por las actrices del cine del destape como modelos estéticos. La niña reserva este juego para la intimidad de su espacio propio, solo compartido con su amiga, y vedado a su madre y a los adultos, pues en ella hay un sentimiento de pudor hacia ese cuaderno.
} 
A continuación, despliega sin tapujos esa fragilidad peligrosamente arraigada dentro de sí, que la convierte en una rehén de su trabajo y la conduce a una suerte de autoexplotación para poder sobrevivir y competir en pie de igualdad con sus homónimos varones:

\begin{abstract}
Me siento el territorio de violencias físicas, psíquicas y laborales [...]. Guardo cada una de mis actividades en un currículum de más cien páginas que actualizo diariamente porque sospecho que alguien pensará que todo lo que tengo me lo han regalado por mi cara bonita o por mi cara feíta. Por el virtuosismo de mis felaciones. Archivo, guardo, documento, doy el do de pecho en cada reunión de trabajo o acto público. (Sanz 2018b: 35)
\end{abstract}

Si Marta Sanz se atreve a unir la brecha de género con el temor a la precariedad, es porque conoce el poder transformador del feminismo, su capacidad para frenar los avances del neoliberalismo; sabe que las demandas de las mujeres implican un cuestionamiento de todo orden de cosas y la propuesta de otros modos de pensar y de hacer, mediante la creación de alternativas críticas. Su angustia, esa angustia visceral ante el mundo laboral, no es un problema personal de la autora, sino que su voz se convierte en la cara visible de un porcentaje elevado de mujeres que sufren la opresión de una enfermedad sin nombre, un dolor que localizará en la clavícula en su obra de 2017.

Tal y como expone Cristina Somolinos Molina, Sanz "da cuenta de una cotidianidad corporeizada y, por tanto, se centra en la manera como los individuos, en sus coordenadas sociales singulares, dan sentido a sus actuaciones diarias" (2018). En su argumentación, Somolinos toma de Adrienne Rich la noción del cuerpo como territorio convertido en lugar de enunciación para las mujeres, de forma que cuerpo y lenguaje se reclaman mutuamente y consolidan un espacio de resistencia. Así, pone de relieve el potencial subversivo de los discursos del cuerpo y su concepción como artefacto político en tanto este depende de las condiciones sociales en las que se inserta y de las lecturas sociales que de él se extraen. La investigadora concluye que, en las novelas de Marta Sanz, "se da cuenta de las contradicciones con respecto a los cuerpos que los discursos dominantes han articulado" y que el cuerpo es para su autora "el símbolo en el que se leen las estructuras sociales, culturales e históricas y al mismo tiempo es una ubicación, una posición desde la que se toma la palabra o desde la que no es posible hacerlo" (2018). Un ejemplo de ello lo encontramos en el propio ensayo Monstruas y centauras, donde se da rienda suelta al dolor físico, infligido al cuerpo, que trasciende la dimensión personal y se descubre como un lugar desde el que pronunciar las heridas sociales, económicas y políticas que afectan con especial crudeza a las mujeres:

Nunca han abusado de mí físicamente, pero siento que han abusado de mí todos los días: en el trabajo, con la autoexigencia que yo misma me impongo y para pagar las facturas. Abusan de mí cuando sé que no me puedo negar a casi nada -no puedo- y siento que mi dolor físico, mi ansiedad y mi miedo forma parte de una tríada punzante, y que ese tridente se hunde más en la carne 
de las mujeres empobrecidas, paradas, con pensiones de viudedad ridículas, presas de los ansiolíticos y de las consultas donde aún no se comprenden sus patologías porque no están codificadas en un lenguaje adecuado. (Sanz 2018b: 97-98)

De ahí la insistencia de la escritora en la necesaria recolección de los relatos de las mujeres, y en la revisión del sustrato cultural que subyace en nuestros discursos, que se han alimentado de una visión sesgada del mundo por la educación heredada. Sanz admite que existen raíces dentro de cada una de nosotras -ella reconoce las propias- en las que afloran referentes masculinos, y esas voces se entrecruzan con los dictados personales, con los sueños y los deseos. En clave de humor y haciendo gala de una exquisita ironía, señala a ese habitante invisible, un "hombrecito" que no ceja en su empeño por manipular a las mujeres en su pericia vital, y que recibe una variedad amplia de nombres tales como "Fermín de Pas", "doctor Bartoldi" e incluso "conejito Tambor" (2018: 32). En una entrevista concedida a Jot Down declaró que situarse en pie de igualdad con los hombres no quiere decir neutralizar las diferencias con ellos y "escribir como un hombre", sino que es preciso reivindicar una visión y un discurso de las mujeres, pese a que, de forma inevitable, esté atravesado por "el lenguaje del opresor" (en Bonet 2016). Ejercer una posición crítica frente a aquellos presupuestos que se despliegan a nuestro alrededor, interrogar al texto, dudar de ciertas representaciones y, en su lugar, buscar otras: todas estas actitudes resultan importantes para llevar a cabo una praxis feminista. Aunque en Monstruas y centauras tenemos el ejemplo más claro de un discurso comprometido, nos aproximaremos ahora a otros ensayos y artículos que nos permiten examinar con más profundidad su posición autorial en su intersección con la escritura del cuerpo y, más concretamente, la escritura de un cuerpo doloroso, de una piel que se estira para dejar paso a la herida que supura: como veremos, en ella se fragua la crítica hacia las posiciones ideológicas hegemónicas.

\section{Estrategias literarias PARA CONStRUiR UN TEXTO INCÓMOdO}

La de Marta Sanz es una escritura sin paliativos: con su bolígrafo como única arma -eso sí: cargada de futuro-, la autora localiza la herida y, una vez en el punto de mira, se detiene a examinarla muy de cerca, para luego hundirse sin remedio y sin temor en el mismo centro de la llaga. Como afirmaba la poeta argentina Alejandra Pizarnik, "escribir un poema es reparar la herida fundamental, la desgarradura. Porque todos estamos heridos" (2015: 312). ${ }^{6}$ Y esa senda intrincada, que se sitúa en las antípodas del camino fácil, es la que nos invita a recorrer Sanz en sus obras.

La autora ha arrojado en varias ocasiones una serie de pistas sobre sus razones para escribir lo que escribe y del modo en que lo escribe: Sanz va dejan-

\footnotetext{
${ }^{5}$ Sanz cita el poema de Adrienne Rich "Arden papeles en vez de niños" en el que termina diciendo: "este es el lenguaje del opresor/ y sin embargo lo necesito para hablarte" (2018b: 33).

${ }^{6}$ En la entrevista titulada "Algunas claves de Alejandra Pizarnik", realizada por Martha Isabel Moia y publicada originalmente en El deseo de la palabra (Barcelona: Ocnos, 1972).
} 
do al lector un puñado de migas de pan para que no se pierda en medio de la selva literaria. Un ejemplo claro de esta radiografía que nos habla de su posición autorial dentro del campo literario se encuentra en el volumen de ensayos No tan incendiario (2019). Se trata de una muestra de la mejor urdimbre de Sanz, un conjunto de textos que pretenden hurgar en terreno pantanoso y, por tanto, generar incomodidad, no dejar títere con cabeza ni respuesta sin una lluvia de preguntas. En ellos desgrana, desmonta y echa por tierra cualquier tipo de certeza asociada al valor de la literatura en nuestros días. Así, leemos:

\begin{abstract}
Propongo escribir textos que duelan. Frente a las visiones edulcoradas de la realidad, toda la literatura tendría que doler y alejarse de esas bonitas perspectivas irónicas que no son más que un tupido velo para tomar distancia y separar 'inteligentemente' los labios sin causar muchas molestias practicando el ejercicio de la corrección política. La autocensura. La actitud que garantiza un lugar en el mundo. (Sanz 2019: 82)
\end{abstract}

Quienes se acerquen a este libro tratando de hallar respuestas claras probablemente queden decepcionados, porque si Sanz ha volcado sus pensamientos en estos textos cuyo tema principal es el sentido de la literatura en nuestros días y su imbricación indisociable con la política, ha sido a través de la interrogación constante. Como ella misma afirma en las palabras preliminares, "responden a la incertidumbre y a cierta sensación de malestar". Son ensayos "esquizoides" que mezclan un abanico admirablemente amplio de referencias culturales procedentes de distintas esferas y en los que consigue asomar la cabeza para enarbolar la daga de la crítica: nos encontramos desde la denuncia hacia la falta de compromiso de la cultura de izquierdas, hasta la comodidad generalmente perseguida por muchos lectores que buscan en la literatura una respuesta que no les saque de su zona de confort.

¿Qué es lo que empuja a Sanz a escribir textos que no dejen incólumes a sus lectores? Aunque sería muy osado tratar de responder a esta pregunta, quizá podamos hallar una solución en la perspectiva autobiográfica. En la entrevista ya citada a Jot Down, la autora afirma que persigue un estilo perturbador porque ella misma, como receptora, disfruta de las lecturas que la afectan y trastocan en mayor o menor medida: "Valoro mucho la literatura de la que no salgo indemne. Valoro mucho la literatura que de algún modo me golpea en el buen o mal sentido de la palabra y lo que hace es ampliar mi visión del mundo, mi manera de ver las cosas" (en Bonet 2016). Sanz exige en el lector una posición activa, que se plantee preguntas, que no se acomode con aquello que le proponen los textos. A continuación, afirma lo siguiente: "adopto esta actitud porque en los textos literarios me parece que lo que se dice es lo mismo que la manera de decirlo. El estilo es la ideología, y el estilo y la ideología pueden coincidir, o no, con el estilo canónico y el discurso dominante" (en Bonet 2016). Es decir, desde su punto de vista aquello con lo que se ejerce la ideología de una forma irremediable es el lenguaje, de modo que, tanto en sus obras literarias como en sus ensayos, la autora incide con especial firmeza en la forma en la que construye su discurso, pues sabe que es en él donde se desplegará la artillería del pensamiento. 
En su artículo "Crueldad y amor", publicado en El Salto el 24 de febrero de 2020, Marta Sanz revela una vez más cuáles son las dificultades con las que una escritora se encuentra en su quehacer cotidiano. Comienza reivindicando el derecho a la queja, a pesar de que se ha convertido en una autora reconocida, con varios premios destacados a sus espaldas, y que publica en una editorial de primera línea como es Anagrama. Sanz utiliza ese altavoz que le proporciona poseer una columna en un diario público para revelar que el oficio de escritor es muy a menudo un oficio de supervivientes porque no es posible pagar las facturas gracias a las producciones literarias: además, debe dar clases, conferencias en universidades, charlas en bibliotecas, asistir a clubes de lectura o impartir talleres. Si bien sabe que, en cierto modo, dedicarse a su trabajo es un privilegio, la sombra de la precariedad se encuentra siempre al acecho. Leyendo estas líneas de Marta Sanz resulta inevitable pensar en El entusiasmo (2017), de Remedios Zafra, donde desmenuza y derriba muchas de las creencias y prejuicios que existen dentro del campo de la creación intelectual y la cultura: la precariedad se cierne sobre estos trabajos, que a menudo se asocian con hobbies o con labores que se llevan a cabo por gusto propio. Además, esta situación se agrava en el caso de las mujeres:

\begin{abstract}
Llama la atención cómo empleos creativos y culturales hoy siguen un camino donde la ambigüedad ha sido empleada para difuminar su trabajo, bajo perversas formas de consideración que hacen borrosa su denominación y pago. Alimentar un sistema apoyado en el entusiasmo y en la suficiencia de un pago inmaterial es otro factor que nos resulta tristemente familiar. Bien promoviendo la resignación o bien sustentándose en la idealización de prácticas vocacionales, afectivas y altruistas, allí habita mucha precariedad feminizada, ese terrorífico mito de las mujeres que ya están pagadas con el "amor que reciben". (Zafra 2017: 200)
\end{abstract}

Sanz coincide con que, dentro del microcosmos de la literatura, las mujeres se encuentran en clara desventaja, pues si bien en la actualidad se visibiliza más su obra, a menudo esto se entrecruza con intereses de fondo y con una perversa adscripción a una moda dentro de un campo cultural obcecadamente machista. Se ejerce hacia ellas una constante presión, se miran con lupa sus acciones, se examina su relación con sus compañeras y con su genealogía, se subraya su aislamiento en otras ocasiones. Lo que la escritora detalla no resulta muy distinto de aquello que ya ponía sobre la mesa Joanna Russ en Cómo acabar con la escritura de las mujeres: desde sus comienzos, la escritura de las mujeres ha sido recibida desde la suspicacia y la mirada escrutadora de la crítica, predominantemente masculina. Russ propone una categorización de los juicios despreciativos que se han esgrimido para disuadir el ejercicio literario de las autoras, tales como la negación de la autoría, el desprecio hacia las experiencias femeninas volcadas sobre el papel o el recurso al "mito del éxito aislado", es decir, el reconocimiento de una sola obra frente al olvido de la mayor parte de su producción (2018: 145). Así, en esta lucha perpetua por entrar a formar parte del canon, las autoras actuales como Marta Sanz reconocen que es preciso adoptar una actitud de permanente vigilancia, pues 
la literatura, al igual que otras prácticas artísticas, continúa siendo un territorio agreste para las mujeres que toman la palabra.

\section{LA LECCIÓN DE ANATOMÍA: DISECCIÓN DE UNA VIDA}

En 2019 Marta Sanz edita un volumen titulado Tsunami. Miradas feministas, en el que reúne un coro de voces de mujeres que trabajan dentro de la esfera cultural y literaria, y les pide un relato personal, una mirada feminista sobre la realidad. En el prólogo del libro defiende la importancia que tiene esta ceremonia en la que todas comparten sus vivencias; gracias a esta visibilización se refuerza la toma de conciencia de una situación que trasciende la intimidad, porque lo personal es también político, porque los infiernos de muchas han sido experimentados por otras mujeres. Además, Sanz revela que en la utilización por parte de las mujeres del género autobiográfico hay una justa reapropiación, ya que tradicionalmente ha sido un discurso denostado por el hecho de poner el punto de mira en la cotidianidad, en los hechos íntimos fuera del espacio público, en ese universo privado que ha sido el reservado para las mujeres:

Los géneros autobiográficos de la escritura femenina siempre se han considerado obscenos, no tanto por practicar una pornografía o una corporalidad aparentemente groseras e innecesarias, sino por enfocar lo nimio, lo poco importante, lo que por su intrascendencia debería permanecer fuera de escena. (Sanz 2019: 15)

En su ensayo Le journal intime (1991), la crítica francesa Beatrice Didier destacaba el hecho de que los textos que formaban parte de los llamados "géneros menores" (autobiografía, diarios, epistolarios) normalmente nacían en el ámbito privado y permitían a sus autoras saltarse las reglas al situarse en las afueras de lo institucional. La libertad de la que los textos femeninos han hecho gala debe convertirse en una fortaleza y también en un signo distintivo de su escritura. Hemos querido rescatar este testimonio para volver la mirada hacia la autobiografía en la obra de Marta Sanz y, más concretamente, aproximarnos a una novela que resulta un verdadero autorretrato, La lección de anatomía (publicado en 2014 y reeditado con algunas modificaciones en 2018, respondiendo a su deseo de ampliar la obra y corregir algunos detalles). Resulta especialmente revelador el prólogo que acompaña al volumen, escrito por Rafael Chirbes, en el que nos recuerda que su título remite a ese lienzo magistral de Rembrandt, "La lección de anatomía del doctor Nicolaes Tulp". Desde el dramatismo del claroscuro, asistimos a la contemplación de una autopsia, nos asomamos al interior de un cuerpo humano. Chirbes se encarga de remarcar las diferencias entre esta "lección" de Marta Sanz y la narración épica característica de las autobiografías, relato que busca una complicidad de los lectores y araña una posición de poder; por el contrario, la autora, que es a su vez la narradora y protagonista de la historia, hace uso de una narración que está próxima a la picaresca, porque quien lleva las riendas de la historia muestra una especial habilidad para manejar los hilos con una pericia que resulta un verdadero reto para los lectores. Sanz tan pronto muestra una mirada implacable como ines- 
peradamente permisiva; además, reivindica el derecho a equivocarse o el derecho a mentir. Por ello, afirma Chirbes:

\begin{abstract}
En este libro, Sanz aspira a algo más que a autorretratarse: trabaja en una literatura de intervención que obliga al lector a ponerse en el sitio en el que no quiere estar, porque desde allí acaba viendo lo que nunca debería ver, eso que, una vez descubierto, te parece tan evidente que ya no puedes quitártelo de encima. Su finísima capacidad de observación le permite llevar a cabo la tarea que le pedía Proust al verdadero artista: someter al espectador a ciertas maniobras desagradables del modo en que lo hace el oftalmólogo, unas cuantas manipulaciones en el punto de vista que, una vez concluidas, le permiten al paciente contemplar de un nuevo modo cuanto tiene alrededor. (Chirbes 2018a: 11-12)
\end{abstract}

Lo que el escritor quiere señalar es, precisamente, que Marta Sanz, a lo largo de este relato que atraviesa su infancia y adolescencia hasta llegar a la vida adulta, dirige al lector hacia posiciones inesperadas y lo expone a riesgos con los que quizá no había esperado encontrarse. Nos parece muy significativo lo que subraya Natalia Vara Ferrero a la luz de las peculiaridades del discurso autobiográfico en Marta Sanz. Desde su punto de vista, la autora, tanto en sus poemarios como en La lección de anatomía, no describe la identidad como un proceso unipersonal sino relacional, de forma que incide en un aspecto clave en estas obras de Sanz: su recurso a la memoria como una revisión del pasado a partir de las relaciones con aquellos junto a los que ha ido construyendo su identidad, sin olvidar el contexto sociohistórico en el que su historia se inscribe (Vara 2018: 3).

Otro aspecto que resulta remarcable es el énfasis en la inscripción del cuerpo en su narrativa, y especialmente aquella que está vinculada con los cambios en los cuerpos de las mujeres en su etapa de maduración. Esta presencia de la corporalidad a partir de la textualidad se convierte en un eje que sustenta el discurso en La lección de anatomía. Desde la primera oración de la obra la narradora se encarga de hacernos llegar su visión atroz del alumbramiento, en el que su madre por poco muere desangrada. A propósito de este relato con tintes grotescos, Violeta Ros Ferrer traza un paralelismo entre la escritura llena de "fluidos corporales que impregnan la narración" en Sanz y el autorretrato de la pintora mexicana Frida Kahlo titulado "Mi nacimiento", en el que muestra la imagen del parto como un momento fundacional del relato de vida (Ros 2018: 9). En los capítulos que siguen se enumeran las dietas especiales, el reconocimiento de los cambios físicos y hormonales, así como el continuo enfrentamiento con un cuerpo que no siempre resulta amable sino todo lo contrario. También relata algunos descubrimientos tempranos vinculados a la sexualidad activa femenina, como en el hilarante capítulo "un experimento que provocó la firme promesa de mi celibato", en el que narra cómo surge esa precoz promesa incumplida a partir de un ingenuo experimento consistente en esconderse tras la cisterna del retrete de su casa y esperar a que los hombres -desde familiares hasta amigos de la familia- tuvieran que utilizarlo. Tras haber pasado revista a un número considerable de penes, la narradora sentencia que se trata de un órgano feo, polimorfo y desagradable, con el que no desea ninguna aproximación (2018a: 48). 
Jon-Romeo Precioso destaca la imagen reveladora de la "sangre de la escritura", que le sirve a Sanz como "metáfora de las heridas que encuentran su traducción en y a través de la escritura" (2012: 102). La narradora describe una escena de ensimismamiento ante el hecho de observar a otra estudiante que ha cubierto de sangre la página en la que escribe. Asimismo, nos parece muy significativo un capítulo titulado "retrato y autorretrato", en el que se obsesiona con que alguien plasme su rostro con pinceles y ella misma toma lecciones de pintura con su tía Pilar, pero finalmente acaba reconociendo la imposibilidad de la ejecución de su propio retrato. Desde la inocencia adolescente, reconoce las máscaras de la identidad y trata de fabricarse una a medida. "Yo misma ignoro cómo manejar los pinceles para retratarme del modo que aspiro a ser", confiesa la autora, y a continuación reclama su derecho a escribir porque la literatura le permite ofrecer un retrato veraz de sí misma: "No me ha quedado más remedio que tomar la palabra, porque nunca encontré un pintor con destreza" (2018a: 80).

En su texto preliminar, Chirbes remarca que lo único que la autora puede presentar de sí misma es aquello que está vinculado al cuerpo: "Acabada la lección, que fue repaso de un catálogo de máscaras, en el teatro anatómico literario ya sólo queda mostrar lo que había debajo de ellas: el cuerpo, la pura carne desnuda" (2018a: 15). Con la fusión de los cuerpos de la narradora y de la protagonista, Marta Sanz no flaquea ni desea esconderse o rehuir la mirada -la lectura- de los espectadores. De este modo, la escritora no se oculta, sino que precisamente utiliza la autobiografía como un espacio de libertad en el que reclama su derecho a la autoría, una autoría femenina en la que el cuerpo se revela como un claro protagonista. Natalia Vara Ferrero pone de relieve que uno de los valores del "hipergénero autobiográfico" que maneja la autora es que subvierte esta modalidad escritural, de manera que rehúye los modelos más ortodoxos (2018: 2). En el último epígrafe del libro, titulado "desnudo", leemos un párrafo muy revelador en el que recupera el motivo anteriormente mencionado del autorretrato:

Cada palabra es un modo, más o menos honesto, de autorretratarse. Llevo mi honestidad hasta el impudor del desnudo. Mi autorretrato desnudo se colgará en la sala de un museo. Alguien entrará y lo mirará y dejará de mirarlo. El contemplador dará vueltas alrededor de la sala, se detendrá frente a otras obras. De pronto algo le hará girar sobre sus talones para descubrir quién le persigue. Se fijará otra vez en mi desnudo. Reparará en los ojos adormecidos. Volverá de nuevo sobre sus pasos. Mirará por tercera vez y, como un niño que juega al escondite, procurará escamotear su cuerpo. Lo mire desde donde lo mire, desde el punto más recóndito o lateral de la sala, el contemplador no lo podrá evitar: soy yo la que le está mirando. (Sanz 2018a: 357)

Con estas líneas la autora da una vuelta de tuerca a la relación entre objeto y sujeto, entre escritor y lector. Es ella quien dirige su mirada, su desnudo hacia nosotros, es ella quien interroga: se alza definitivamente como aquella que contempla en lugar de ser la mujer vista desde la perspectiva masculina. No es la musa, como 
había reivindicado en la infancia, sino la creadora, la escritora. Su autorretrato, si acaso es posible pintar uno, tiene su origen en el papel y la tinta. En La lección de anatomía la narradora y la autora se miran directamente a los ojos sin pestañear y deciden mostrar todo aquello que tradicionalmente se ha considerado como impúdico. Para comprender la posición desde la que habla Marta Sanz será necesario remitirnos a ese otro libro ineludible de la autora, Clavícula (2017), una obra inclasificable, una retahíla perfectamente construida en la que la escritora permitirá que el dolor se canalice a través del lenguaje. Un mapa de las cicatrices que nos convierten en seres frágilmente humanos.

\section{Clavícula: pronunciar el dolor femenino}

Si en La lección de anatomía nos encontrábamos con una suerte de bildungsroman en la que la identificación entre el cuerpo de la narradora y de la autora podía subrayarse en muchos de los capítulos, en Clavícula Sanz se distancia deliberadamente de la ficción para nombrar el cuerpo fracturado y acorralado por el dolor, tal y como afirmó en una entrevista (Morales 2017). Esta es una obra que no se podría etiquetar como una novela, sino más bien una suerte de monólogo fragmentario en el que la autora entrelaza las razones del cuerpo con las peripecias laborales que atañen a la escritura. En la misma entrevista, la escritora subraya que "la fractura del cuerpo literario tiene que ver con la fractura del cuerpo real", de manera que las variaciones y mutaciones en el propio género discursivo atienden a la experiencia personal del dolor y su impacto en el cuerpo. En otra conversación en torno a la publicación de esta obra, Sanz reafirma ese estrecho vínculo entre el cuerpo y la escritura, de manera que se afectan o contaminan mutuamente:

Siempre activo la metáfora de que el texto es un cuerpo y viceversa. El cuerpo es un texto en el que se te quedan marcadas todas las cosas que has vivido, pero, a la vez, el texto literario se desestructura por efecto del dolor del cuerpo, o se llena de referencias sensoriales. (Sanz en Blanco Medina 2018)

Tal y como señala Andrea Kaiser Moro, "la voz narrativa de Clavícula es, así, aullido y reivindicación de aullido: la representación de un dolor que no se enmascara bajo máscaras de ficción (en las que la autora se reconoce impostora) sino que busca articular su cauce" (2018: 194). Sanz sustenta su discurso en una defensa tenaz de un complejo continuum entre la esfera personal del mundo íntimo y la incidencia del sistema económico en las circunstancias individuales y colectivas. Es preciso mancharse las manos, es preciso canalizar el bombeo de la sangre, las arritmias del corazón, en la escritura. Pese a que lo habitual en su narrativa es encontrarnos con una enumeración ad infinitum, rica en matices y detallismo, en Clavícula descubriremos algunos textos de este tipo mezclados con otros en los que la prioridad es la síntesis de las reflexiones mediante la elección de palabras precisas como un bisturí. Este párrafo es un buen ejemplo de ello:

Cuando escribo -cuando escribimos- no podemos olvidarnos de cuáles son nuestras condiciones materiales. Por eso pienso que todos los textos son au- 
tobiográficos y a veces la máscara, las telas sinuosas y las transparencias que cubren el cuerpo son menos púdicas que una declaración en carne viva. [...] La autobiografía es la consagración de la realidad y de la primavera, y no las costuras para convertirla en un relato. El estilo es hablar de la tripa que se me ha roto. (Sanz 2017: 50)

Clavícula se abre con una cita de Marguerite Duras, procedente de su ensayo Escribir, en el que la autora se adentra en las profundidades de sus infiernos personales, donde halla en la soledad un cuarto propio desde el que escribir; así, se refiere a la escritura como un acto salvaje, anterior a la vida, y afirma: "Uno se encarniza. No se puede escribir sin la fuerza del cuerpo" (1994: 24). Como otras autoras de la tradición francesa del siglo xx, Duras mantiene una deuda con la "escritura femenina" anunciada por Hélène Cixous en su célebre ensayo La risa de la medusa (1995). En dicha obra proclamaba una indagación en el inconsciente y el deseo, una liberación del pensamiento en la que el texto y el cuerpo pueden fluir acompasadamente gracias al lenguaje poético. A través de esta escritura del cuerpo es como puede emerger con más fuerza y singularidad el discurso de las mujeres. El cuerpo se convierte en cuerpo simbólico por haber sido tradicionalmente negado y violentado por la cultura patriarcal. "Escríbete: es necesario que tu cuerpo se deje oír", proclamaba Cixous (1995: 26) y, al mismo tiempo, reconocía la imposibilidad de definir la práctica de la escritura femenina utilizando las herramientas del sistema falocéntrico, puesto que "no se puede teorizar, encerrar, codificar", es decir, en su propia esencia recoge el hecho de ser contingente y cambiante. Cixous insiste en afirmar que para las mujeres el hecho de tomar la palabra es un privilegio, una conquista, que se asume desde un cierto desgarramiento y temblor.

Clavícula nos habla del temblor: recoge los rastros de un dolor indecible, que aparece en medio de un vuelo en el que la autora atraviesa el Atlántico, y cuyo centro reconoce, precisamente, en la clavícula. El dolor se va tejiendo a través del acto de la escritura, una escritura que no termina de decantarse por un género literario concreto, sino que va mutando. Así, conviven el estilo diarístico con la crónica, los retratos de seres cercanos y las lecturas, la correspondencia por correo electrónico en la distancia con su compañero de vida, las confesiones a media voz y los anhelos imposibles. Una vez más, y quizá en esta ocasión con más rotundidad, Sanz recupera su propósito de no regalar a los lectores un texto cómodo, sino una sucesión de confesiones rebeldes que responden a su voluntad de urdir piezas incómodas, tal y como reza en estas líneas: "me gustan los libros que producen orzuelos. Los que abren estigmas en las palmas de las manos. Los que aprietan la garganta y nos cortan la respiración" (2017: 87).

Ese dolor, que no deja de crecer, toma la forma de lo animal, de una criatura viva, y es descrito haciendo gala de un lirismo propio de Sanz, a medio camino entre una hipérbole irónica y una mirada llena de ternura. De este modo, afirma: "[El dolor] Es un ratoncito que cambia de tamaño y de forma dentro de su jaula, [...] es un huevo de jilguero [...], un pez nadador [...], un musgo [...], es un olor que no se va" (2017: 45). También lo describe como "veneno de medusa" (2017: 17) o "mi misteriosa enfermedad, mi cabeza de alfiler, mi garrapata" (2017: 19). Ese dolor del que Sanz nos habla y que provoca miedo es un dolor femenino, que en 
algunas ocasiones relaciona con la menopausia y con otras enfermedades de difícil diagnóstico sufridas por las mujeres como la fibromialgia o la endometriosis. Los lectores no conseguirán averiguar el nombre de esta enfermedad misteriosa tal vez porque ni la propia autora lo sepa, pero sí intuimos que es un temblor muy vinculado con las condiciones materiales, especialmente con la precariedad laboral que le impide mantener una estabilidad económica. Además, la enfermedad se erige como una barrera que la separa de la escritura, le provoca gran inseguridad hasta el punto de que se convierte en el único pensamiento, una obsesión que necesita vencer para volver a recuperar su lugar: "El dolor me afea la letra. Coloniza el cerebro sin dejar espacio para nada más" (2017: 86). Curiosamente, cuando acude a la consulta de un médico y le describe el lugar donde se origina el dolor, le señala un espacio entre el esternón y la garganta, un punto hueco, donde no existe ningún órgano que pueda provocarle la dolencia (2017: 113). Y es que ese lugar donde puede habitar el dolor es precisamente el de la página en blanco.

Ante la pregunta de un periodista, Sanz enarbola su poética: "escribo de lo que me duele". Y añade: "Hoy veo con toda claridad que la escritura quiere poner nombre e imponer un protocolo al caos" (2017: 51). Marta Sanz reclama un lugar dentro de la literatura en el que sea posible escribir sobre aquello que nos provoca incomodidad, y reconoce que solamente puede expresarse desde el testimonio personal para ser coherente con esa escritura que se origina en la piel. A pesar de que este dolor surge de un espacio íntimo, en el momento en que vertebra su discurso a través del tamiz literario la autora debe asumir que se trasciende el ámbito de la intimidad para hacerse eco dentro de la sociedad desde el artefacto político de la página escrita, de modo que el dolor se vuelve "un calambre público" (2017: 89). Con esta apuesta literaria supera la barrera material y simbólica que ha relegado a las autoras a un segundo plano en todas las esferas artísticas y socioculturales. Pues bien, esa escritura del dolor anunciada por Marta Sanz es una escritura que entierra sus raíces en lo más hondo del cuerpo, un cuerpo femenino que no oculta aquello que lo conforma, sino que precisamente lo rescata para articular un discurso urdido con la inteligencia y la valentía de quien decide oponerse a la mirada fetichista masculina que tradicionalmente ha recorrido los cuerpos de las mujeres desde el arte y la literatura. Leer a Marta Sanz es asistir a una lección que va mucho más allá de la anatomía: convierte el texto en un cuerpo y el cuerpo en un texto donde las letras laten al ritmo de un corazón palpitante.

\section{PEQUEÑAS MUJERES ROJAS: LA VIOLENCIA CONTRA EL CUERPO DE LAS MUJERES}

Con el objetivo último de discutir las representaciones de la violencia contra el cuerpo de las mujeres en pequeñas mujeres rojas (2020), de Marta Sanz, resulta pertinente relacionar su propuesta con las críticas que surgieron dentro del sector feminista construccionista en los años 70 gracias a algunas publicaciones que pusieron sobre la mesa el problema de la estandarización del placer visual hegemónico, como el conocido artículo de Laura Mulvey "Placer visual y cine narrativo". 
El artículo tomaba como fuente algunos clásicos de Hollywood para dar razón del instinto de la escopofilia, que únicamente podía combatirse, desde la visión de Mulvey, con una radical desaparición de los cuerpos femeninos estereotipados para que estos dejen de ser un fetiche a los ojos masculinos. Este texto fue objeto de grandes críticas, ya que negaba la posibilidad de una representación subversiva del cuerpo femenino en un contexto en el que se había producido un boom del body-art feminista.

Pese a que esta última obra de Marta Sanz tiene un carácter ficcional, nos interesa especialmente porque en ella existe una clara pretensión política: desde la letra minúscula escogida para la primera palabra del título; hasta la voluntad expresa de rescatar, a través de los hilos de la representación literaria, tanto el tema de la memoria histórica mediante un relato que bucea en las fosas comunes para desenterrar a los muertos anónimos del franquismo, como la desgarradora dureza de la violencia ejercida contra los cuerpos de las mujeres. Como declaraba la autora en una entrevista, "la novela es profundamente política porque es profundamente poética" (en Sigüenza 2020), es decir, la exigencia de la crítica hacia el imaginario cultural que normaliza la violencia hacia los cuerpos de las mujeres puede hallar su mejor vehículo de expresión en la capacidad de evocación de la metáfora. Según Sanz, "la novela nace del presentimiento de que la ficción es verdad, de que los relatos se nos meten en la carne". En pequeñas mujeres rojas se nos relata una historia contada desde varios puntos de vista: se engranan las voces de Paula, que se comunica a través de cartas con Luz Arranz, la madre de su marido el detective Arturo Zarco; las voces de los muertos, que asoman en los capítulos en los que reza "leer despacio"; así como la voz de la propia Luz, que, tras su asesinato, trata de despejar las incógnitas de su muerte.

La cristalización de las situaciones violentas que salpican toda la novela culmina con la muerte de Paula, la protagonista, en manos de David Beato, que había sido su amante desde el momento en que ella llega al hostal que regenta su familia. Luz Arranz adopta el papel de narradora tras la pérdida de su amiga y asume el complejo papel de poner voz a la violencia y a la crueldad extrema que se ensaña con el cuerpo de la víctima, sin olvidar que mediante su representación no desea reproducir la mirada fetichista del voyeur sino todo lo contrario. Así, se adoptan diversas estrategias para nombrar desde el lenguaje esta escena descarnada con un estilo que trata de huir del estereotipo de exhibición de la violencia contra el cuerpo de las mujeres. Sanz comienza este capítulo con una descripción objetiva y analítica de un aparato que sirve para inmovilizar a los animales, administrarles vacunas o realizarles tomas de sangre, mientras se mantiene al animal en una posición de suspensión. Este aparato no está pensado para su empleo con personas y, sin embargo, David Beato decide someter a Paula a una verdadera tortura previa a su muerte. Conforme va relatando los acontecimientos, Luz Arranz apela a su hijo, Arturo Zarco -que no toma la palabra en esta novela, pero sí ha sido evocado tanto por Paula como por su madre-, ante el que parece dar testimonio de lo sucedido, aunque en última instancia está transmitiendo a los lectores cuál es su posición con respecto a la narración de los hechos. Aquello que Sanz desea rehuir en boca de Luz Arranz es una posible 
visión sexualizada - de una escena que no está exenta de sadismo- en la que el sujeto femenino se convierte en un mero objeto casi sin vida en manos de su torturador:

No soy tan salvaje ni tan impúdica, Arturo Zarco, como para reconstruir los devastadores efectos que provocó este artefacto en el cuerpo de Paula. No voy a proyectar una pornográfica snuff movie en la que certifiques por qué lugares y cuántas veces fue violada, qué laceraciones y amputaciones sufrió, cómo finalmente pereció. (Sanz 2020: 284)

Unas líneas más adelante, escribe: "Con la descripción del artefacto es suficiente". Y repite hasta en catorce ocasiones esta misma oración, como un mantra, a lo largo de las siete páginas que comprende el capítulo. Efectivamente, al trazar un esbozo de la mecánica de esa suerte de jaula sanguinaria, la narradora nos está abriendo la posibilidad de imaginar a la mujer siendo retenida en su interior, como si se tratara de un animal indefenso con el que el cazador desea ensañarse, cobrarse su venganza. A continuación, no encontramos una descripción morbosa del cuerpo femenino violentado, sino que se recurre a la enumeración de una serie de palabras que infligen dolor, que la propia Sanz llega a llamar "palabras-cepo" por su densidad semántica. Este párrafo es una muestra de cómo se obliga al lector a mirar cara a cara un escenario real, sin decorados, sin artificio, donde no cabe la ficción y se rechaza la posible espectacularización de la escena:

Con la descripción del aparato es suficiente.

Permite reproducir mentalmente el escorzo, el estiramiento muscular. El desquiciamiento. La piel rota y las articulaciones descoyuntadas. [...]

No le vamos a poner color ni banda sonora a la escena. No vamos a calcular los minutos de metraje. [...]

Tan solo piensa en las palabras: sangre, marcajes, descornado, guillotina, atrapadora, collera, blocaje, corvejones... piensa en cómo las palabras aprietan y retuercen la carne que se deposita dentro de ellas. Las palabras-pesa aplastan. Las palabras-cepo desgarran y paralizan. Despersonalizan. (Sanz 2020: 285)

Lo que se pretende con esta despersonalización es incidir en la violencia del propio lenguaje, en su descarnada precisión científica. Y es que, pese a repetir una y otra vez "con la descripción del aparato es suficiente", la implicación de quien escribe es absoluta ya que se enfrenta con el dilema de la representación. De esta manera, a lo largo del capítulo se libra un pulso doloroso con la forma de contar, con la elección del estilo y el grado de explicitud. Luz Arranz traslada al lector el dilema ante la posibilidad de pronunciar lo obsceno, aquello que está fuera de escena, o bien adoptar una posición de distanciamiento de los hechos narrados. Una de las oraciones elegidas para referirse a esta tortura hacia el cuerpo femenino es la siguiente: "ahora lo justo sería decirte que transcribo científicamente las laceraciones de un cuerpo reducido a territorio devastado", lo que nuevamente nos lleva a considerar el cuerpo como el lugar de la enunciación, que, en este caso, ha sido completamente destruido por una muerte violenta. A continuación, reconoce el compromiso radical que exige el mismo lenguaje, la necesaria carga ideológica de 
las palabras: "con los mismos mimbres se tejen los documentales que los cuentos de hadas. No lo olvides nunca. Esa similitud no anula la posibilidad de la crítica. No, no lo olvides" (2020: 286).

De esta forma, la finalidad meramente documental es un engaño perverso, dado que todos los relatos hablan de quien los escribe. Pese a la pugna que mantiene consigo misma causada por el dilema sobre la representación de la violencia, la narradora se hace cargo de lo que tiene entre manos, y sabe que lo puede utilizar en contra de su interlocutor, su hijo Arturo Zarco, al que increpa e involucra en su discurso en repetidas ocasiones: "No sé si quiero dejar de matar y torturar -de matarte y torturarte, Zarco-, porque la palabra me ofrece -digámoslo así- un placebo, un sustitutivo: es una proyección diferida de la maldad y de otros instintos crueles" (2020: 287). La palabra puede convertirse en un verdadero instrumento sanguinario, pero Sanz aclara que su propósito no es dar muestras de su crueldad, sino abrir una puerta, esa "puerta que nadie se atrevería a traspasar", para penetrar en un territorio peligroso, negociar los límites de la representación y buscar la implicación de los lectores. Casi al final de la obra parece por fin dirigirse de forma explícita al lector de pequeñas mujeres rojas mediante la utilización de la segunda persona del singular, que ha vivido en su propia piel la encarnación del dolor:

Ordeno los materiales, inventando ciertas pequeñas cosas para jugar contigo, escatimo lo que no puedo soportar y lo que no quiero que se achaque a mis facultades creativas, lo que no quiero que me ensucie como persona -máscara-, aunque solo sea en forma de sospecha - no soy tan valiente, no puedo exponerme así-, y construyo un relato con el que aspiro a sobrecogerte, incluso a castigarte un poco. Porque te afecta. Porque quiero que te sientas responsable. (Sanz 2020: 288)

Se trata de un párrafo muy interesante porque parece implicar directamente a la autora y a la forma que ha escogido para contar el mismo relato. Finalmente, pone sobre la mesa la posibilidad de huir de la representación y no mancharse las manos, o como recomendaba en los setenta Mulvey, abogar por la desaparición absoluta del cuerpo femenino. En este caso, la narradora se pregunta si es legítimo el recurso de la elipsis, si aquello de lo que no se puede hablar es mejor eliminarlo del texto: "Me pregunto si es más inmoral estar callados o hablar irreflexiva, desconsideradamente". La conclusión es consecuente con la historia que se relata en esta novela, es decir, la elipsis resulta del todo inoportuna porque, aunque no se pueda verbalizar cada pequeño detalle por su tremenda dureza, el silencio sepulcral evadiría el compromiso ideológico.

Así, el cuerpo emerge con fuerza en este texto porque precisamente el texto se llena de las magulladuras, de los desgarramientos de la carne, del exceso que nace, crece y se expande con las palabras. Marta Sanz maneja con sensibilidad y destreza este delicado equilibrio y compone un lienzo que es casi irreproducible, un relato obsceno porque no es el relato que normalmente nos habrían contado, sino la escritura de lo que queda fuera de escena. El tabú. El grito femenino. 


\title{
CONCLUSIÓN
}

\begin{abstract}
Escribir es ir tatuándose el cuerpo al mismo tiempo que descubrimos todo lo que ya tenemos escrito sobre la piel. La arruga, lo flácido, el sentimiento de la felicidad, o las proximidades de la muerte. Nuestros deseos, nuestros trabajos. El retorno al punto de partida. Nombrar el cuerpo, conquistar el territorio: en eso consiste escribir. (Sanz 2018: 71)
\end{abstract}

Con estas palabras extraídas de La lección de anatomía recogemos los postulados que se han puesto de relieve en este artículo, y que se condensan en la creación de un verdadero corpus textual en la obra de Sanz, donde la escritura de un texto abre la posibilidad de inscribir en él una huella corporal del sujeto. Tras revisar las últimas obras publicadas por la autora, dos de ellas de corte autobiográfico, podemos afirmar que en estos textos existe una voluntad de volcar sobre el papel las pulsiones del cuerpo, ya que son un mapa de cicatrices gracias a las cuales es posible hablar desde una libertad mayor; el texto se erige como una instancia que va más allá de los géneros (textuales, sexuales) para nombrar lo que duele. Si tuviéramos que bautizar de alguna forma a este estilo -"el estilo es hablar de la tripa que se me ha roto"- sería conveniente hablar de una escritura en la que el texto es inseparable del cuerpo, un cuerpo de mujer que no renuncia al relato de su experiencia desde la subjetividad. Un cuerpo de mujer que, en Clavícula, nos muestra su rostro como herida, el espejo de una enfermedad invisible cuyo padecimiento abruma en tanto se ignora dónde se origina el dolor. Un cuerpo de mujer que, en La lección de anatomía, se narra desde el alumbramiento, que nos habla sin tapujos de la fisonomía femenina y exhibe su autorretrato al desnudo desde la consciencia de una posición que no se permite vulnerabilidad, sino reapropiación del dominio. Finalmente, un cuerpo de mujer roto, despedazado, que en pequeñas mujeres rojas es un homenaje a las víctimas, pero, sobre todo, un grito de justicia hacia la dignificación de las representaciones. Una forma valiente de mirar a la cara al asesino y golpear lo literario desde el lenguaje para no dejar incólumes a los lectores.

\section{OBRAS CITADAS}

Blanco Medina, Eva (2018). "Marta Sanz, la escritora de lo desagradable", ICON. El País. <https://elpais.com/elpais/2018/10/29/icon/1540835867_251761.html> (8 de septiembre de 2021).

Bonet, Paula (2016). "Marta Sanz: Sufrir no nos hace más fuerte, normalmente nos debilita". <https://www.jotdown.es/2016/03/marta-sanz/> (5 de febrero de 2021).

Cixous, Hélène (1995). La risa de la medusa. Ensayos sobre la escritura. Barcelona: Anthropos.

Didier, Beatrice (1991). Le journal intime. París: Presses Universitaires de France.

Duras, Marguerite (1994). Escribir. Barcelona: Tusquets. 
Kaiser Moro, Andrea (2018). "El derecho al aullido: corporalidad y lenguaje en Clavícula (Sanz, 2017)", Feminismos/s, 31: 189-203. DOI: <http://dx.doi.org/10.14198/ fem.2018.31.09>.

Morales, Clara (2017). "Marta Sanz: la queja es una forma de resistencia y rebeldía", InfoLibre. <https://www.infolibre.es/noticias/los_diablos_azules/2017/04/07/marta_ sanz_entrevista_clavicula_63522_1821.html> (9 de septiembre de 2021).

Mulvey, Laura (1988). Placer visual y cine narrativo. Valencia: Episteme.

Pérez Fontdevila, Aina y Meri Torras Francès (eds.) (2019). ¿Qué es una autora? Encrucijadas entre género y autoría. Barcelona: Icaria.

Pizarnik, Alejandra (2015). Prosa completa. Barcelona: Lumen.

Planté, Christine (2019). "La excepción y lo ordinario", in ¿Qué es una autora? Encrucijadas entre género y autoría, ed. Aina Pérez Fontdevila y Meri Torras Francès. Barcelona: Icaria, 97-142.

Precioso, Jon-Romeo (2020). "Du corps visible au corps invisible: les maladies, blessures et cicatrices dans les romans de Marta Sanz", Narraplus, 4: 89-115.

Ros Ferrer, Violeta (2018). "Divagaciones en torno a la imagen del agujero. La Transición en la escritura del cuerpo de Marta Sanz", Olivar: Revista de Literatura y Cultura Españolas, 18 (27). DOI: <https://doi.org/10.24215/18524478e024>.

Russ, Joanna (2018). Cómo acabar con la escritura de las mujeres. Madrid: Barret y Dos Bigotes.

Sanz, Marta (2020). pequeñas mujeres rojas. Barcelona: Anagrama.

Sanz, Marta (2020). "Crueldad y amor", El Salto. <https://www.elsaltodiario.com/literatura/ opinion-marta-sanz-precariedad-escritura> (5 de febrero de 2021).

Sanz, Marta (2019). No tan incendiario. Cáceres: Periférica.

Sanz, Marta (coord.) (2019). Tsunami. Miradas feministas. Madrid: Sexto Piso.

Sanz, Marta (2018a). La lección de anatomía. Barcelona: Anagrama.

Sanz, Marta (2018b). Monstruas y centauras. Nuevos lenguajes del feminismo. Barcelona: Anagrama.

Sanz, Marta (2017). Clavícula. Barcelona: Anagrama.

Sigüenza, Carmen (2020). "Marta Sanz: Me da miedo cómo nos roban las palabras", Efeminista. <https://www.efeminista.com/marta-sanz-pequenas-mujeres-rojas/> (11 de septiembre de 2021).

Somolinos Molina, Cristina (2018). "Mujeres, cuerpos y trabajos en la narrativa de Marta Sanz", Olivar: Revista de Literatura y Cultura Españolas, 27. DOI: <https://doi. org/10.24215/18524478e025>.

Vara Ferrero, Natalia (2018). "Reformulando el sujeto, los géneros literarios y el compromiso con la historia: la escritura del yo en la obra de Marta Sanz", Olivar: Revista de Literatura y Cultura Españolas, 27. DOI: <https://doi.org/10.24215/18524478e023>.

Zafra, Remedios (2017). El entusiasmo. Precariedad y trabajo creativo en la era digital. Barcelona: Anagrama. 